American Journal of Pharmaceutical Education 2018; 82 (7) Article 6317.

\title{
RESEARCH
}

\section{Innovative Approaches to Teaching Dyslipidemia Management in a Required Pharmacy Therapeutics Sequence}

\author{
Laura H. Waite, PharmD, Alice L. Scaletta, PharmD, Diane E. Hadley, PharmD \\ Philadelphia College of Pharmacy, University of the Sciences, Philadelphia, Pennsylvania \\ Submitted February 2, 2017; accepted July 11, 2017; published September 2018.
}

Objective. To describe a novel design on teaching dyslipidemia management that would help students compare and apply past and current clinical recommendations using a variety of new mechanisms.

Methods. Didactic time consisted of three sections: lecture; faculty-led panel discussion; and interactive, progressive, student-driven patient case. The accompanying case studies course involved varying interactive student activities, including literature review, adverse event reporting, and immediate feedback assessment tools.

Results. Students performed well on audience response questions, dyslipidemia examination questions, and in-class case studies activities. Subjective student and faculty feedback were positive for the entire innovation.

Conclusion. The redesigned dyslipidemia module gives students exposure to overall management of this disease state through several innovative approaches that can be repeated in other courses to enhance learning.

Keywords: faculty panel, audience response, literature review and assessment, IFAT, dyslipidemia

\section{INTRODUCTION}

In late 2013, a new set of dyslipidemia management guidelines was published by the American College of Cardiology (ACC) and the American Heart Association (AHA). ${ }^{1}$ Subsequently, additional dyslipidemia management recommendations authored by the National Lipid Association (NLA) were released that contained marked similarities and differences from the ACC/AHA guidelines. ${ }^{2,3}$ To adequately prepare students to care for patients with dyslipidemia in clinical practice, pharmacy education should ideally include a context of the historical treatment approach based on the National Cholesterol Education Panel's Adult Treatment Panel III and updated (2001 and 2004) guidelines, the ACC/AHA 2013 Blood Cholesterol guidelines, and the NLA recommendations. ${ }^{1-10}$ This amount of content requires significant didactic and active learning time, and traditional teaching approaches may not allow students to truly achieve the ability to provide patient-centered care as described by the Center for Advancement of Pharmacy Education's Educational Outcome (CAPE) 2.1. ${ }^{11}$ Additionally, the 2016 Accreditation

Corresponding Author: Laura H. Waite, Department of Pharmacy Practice and Pharmacy Administration, Philadelphia College of Pharmacy, University of the Sciences, 600 S. 43rd St., Philadelphia, PA 19104. Tel: 215-596-8751. E-mail: 1.waite@usciences.edu
Council for Pharmacy Education (ACPE) Standards require a greater focus on active learning pedagogy that allows learners to apply information to practical situations. ${ }^{12}$ Thus, innovative techniques for presenting this content are needed.

Throughout the University of the Sciences Philadelphia College of Pharmacy (PCP) Doctor of Pharmacy (PharmD) curriculum, students are required to participate in two concurrent courses focused on disease state management. In the spring semester of the second professional year (P2), the bulk of the content is delivered in a four credit hour didactic course based primarily on lecture material delivered in large blocks of time (PP466: Human Disease and Application of Therapeutics I), as well as a required one credit hour companion case studies and laboratory skills course (PP468: Practical Lab/Case Studies II) that focuses on application through the use of patient cases and simulation of related skills to enhance understanding of the material. Dyslipidemia is one of the major foundational disease states in this course sequence, as subsequent disease states involve and/or impact dyslipidemia management and pharmacists encounter this disease state regardless of practice setting. PP466 and PP468 are the only courses in the curriculum in which students receive formal instruction on dyslipidemia management. In course offerings prior to spring 2014, this therapeutic module was taught using four hours of didactic lecture 


\section{American Journal of Pharmaceutical Education 2018; 82 (7) Article 6317.}

with minimal interactive content (PP466) and a patient case requiring a formal written assessment and plan for drug therapy (PP468). However, with the spring 2014 offering of the courses and beyond, previous methods would not have allowed adequate coverage of all of the appropriate literature required for students to fully understand the disease state. In the setting of major module revisions and the guidance of Standard 10.3 in the 2016 ACPE Standards, the authors created a novel design for material presentation and application that would

Table 1. PP466 Human Disease and Application of Therapeutics I Course Goals and Objectives Addressed by the Innovation

$\begin{array}{ll}\text { Goals } & \text { Objectives }\end{array}$

Develop the student's:

Knowledge base of common disorders and their therapy in pediatric, adults and geriatric patients.

Skills needed to collect, interpret, and assess information in a patient care setting.

Ability to assess a patient case, determine reasonable alternatives for therapy, select the appropriate therapy and justify that choice.

Ability to apply evidence-based decision making to patient care.
Enable students to perform the following:

Describe/choose/select/classify the epidemiology, pathophysiology, pathology, etiology, diagnostic criteria, disease severity, clinical signs and symptoms, laboratory features, outcomes and cost of disease in pediatric, adult and geriatric patients.

Describe/choose/select appropriate therapeutic (drug and non-drug) options (first choice and alternative) for common disorders and compare and contrast those therapeutic options with respect to dosing, drug interaction, monitoring for efficacy, monitoring for toxicity, patient factors that influence outcomes of drug therapy (including pregnancy, age, pharmacokinetic, cultural background, pharmacogenomics), costs, cost-effectiveness, availability of practice guidelines, approved and unapproved uses.

Given a patient case, a student will be able to:

Collect additional information from other source (laboratory and other study reports, etc.).

Appropriately interpret common clinical findings from the history, physical examination, laboratory, other studies reported.

Determine which pertinent clinical findings are not provided, but are needed for a reasonable assessment of the patient.

Create a complete, organized, prioritized problem list including identifying the most likely problems or diagnoses, when given the requisite information.

Determine which problems are associated with drug therapy as follows: incorrect drug, dose, interval, route of administration given patient characteristic (diagnosis, age, weight, height, renal \& liver function, immune function, pregnancy, etc); no indication for each drug;

need for drug, but no drug used; therapeutic duplication; clinically relevant drug-drug/-disease/-diet interactions or the potential for these interactions; drug-related adverse event/medication error or high risk for such events/errors; noncompliance

Formulate a therapeutic plan including appropriate nondrug and drug therapy (prescription \& nonprescription) for each problem, justifying each choice and streamlining of the pharmacotherapy when appropriate.

State the appropriate short-and long-term goals of treatment for each common problem given the scenario presented, including specific and general (quality of life, disease prevention, promotion of wellness, etc) measures.

Develop a plan to monitor/assess the therapeutic outcomes. 


\section{American Journal of Pharmaceutical Education 2018; 82 (7) Article 6317.}

Table 2. PP468 Practical Laboratory/Case Studies II Course Goals and Objectives Addressed by the Innovation

\begin{abstract}
Goals
Develop the student's ability to:

Provide patient-centered and population-based care based upon sound therapeutic principles and evidence-based data and taking into account legal, social, cultural, economic, and professional issues, emerging technologies, and evolving biomedical, pharmaceutical, and clinical sciences that may impact therapeutics outcomes.
\end{abstract}

Manage informational, medical, and technological resources of the health care system to promote health, provide, assess, and coordinator safe, accurate medication distribution and improve outcomes of medication use.

Communicate effectively and collaborate with patients, caregivers, and other health care professionals and promote a team approach to patient care.

Retrieve, analyze, and interpret the professional, lay and scientific literature to provide drug information and counseling to patients, their families or caregivers, and other involved health care providers.
Objectives

Develop the student's ability to:

Collect, record, and assess subjective and objective patient data to define health- and medication-related problems.

Demonstrate knowledge of and accept responsibility for that knowledge of commonly used medications, formulations and drug products.

Correlate drug- and patient-related variables to identify and assess drug-related problems.

Evaluate how the unique characteristics of patients and patient populations impact manifestations of drug-related problems.

Demonstrate effective communication abilities in interactions with simulated patients, their families and caregivers, and other health care providers.

Communicate so student's ability is consistent with education level, cultural issues, and student is empathetic.

Assess information needs of simulated patients and health providers and apply knowledge of study design and literature analysis and retrieval to provide accurate, evidence-based drug information. help the students compare previous and current clinical recommendations for patients with dyslipidemia as well as apply that knowledge to patient treatment through a variety of new mechanisms. ${ }^{12}$ The authors hoped to employ Standard 10.3's recommended "introduce-reinforcedemonstrate" curricular approach to bolster students' knowledge-application skills. ${ }^{13}$ Course-specific goals and objectives addressed by this innovation are summarized in Tables 1 and 2 .

The purpose of redesigning the dyslipidemia module was primarily to enhance the students' ability to apply the information that they had learned about dyslipidemia to appropriate patient treatment. Anecdotal reports from students and faculty members after previous course offerings indicated a general lack of understanding of the dyslipidemia course material and inability to apply that information to analysis and selection of appropriate drug therapy plans. This innovation targeted a novel method of information presentation along with deeper application of the knowledge during class activities to address this deficit. Another purpose of the innovation involved increasing student engagement in the course. Because the therapeutics sequence is extremely challenging for students, many simply memorize the information provided in class and focus on achieving a specific grade without ever fully understanding the applicability of the content to patient care. Unfortunately, sometimes this lack of knowledge is not manifested until poor performance in experiential settings or even until negative patient/health care professional interactions after graduation. By employing a variety of innovative techniques in conveying the dyslipidemia content, the authors hoped to pique student interest in the importance of the information beyond just the facts and into the reasons for learning those facts. Multiple approaches were used with the goal of reaching students with different learning styles and learning preferences, including many of the methods described by Gleason and colleagues in 2011, so as to incorporate as much active learning pedagogy as possible. ${ }^{14,15}$

\section{METHODS}

PP466: Human Disease and Application of Therapeutics I: The primary platform for didactic content delivery involved four hours of lecture time in PP466 with a class size of approximately 200 students. As described above, this previously consisted of four hours of 


\section{American Journal of Pharmaceutical Education 2018; 82 (7) Article 6317.}

traditional didactic lecture, divided into two class sessions, with approximately 3-5 multiple-choice TurningPoint (Turning Technologies, Youngstown, $\mathrm{OH}$ ) audience response questions per hour instituted throughout that time. To include new treatment recommendations and literature, as well as enhance students' learning, the four-hour lecture time was divided into a new three-part series.

PP466 Hours 1 and 2: didactic lecture. The beginning of the class consisted of primarily didactic lecture based on assigned pre-class readings from relevant guidelines and the course textbook, similar to previous course offerings. However, the number of audience response questions was significantly increased to enhance the interactive component and to ensure that the students understood the important points of the material. During this two-hour block, the students were fully immersed in both the previous dyslipidemia guidelines and the updated dyslipidemia guidelines as preparation for the remaining activities.

PP466 Hour 3: panel discussion. The next hour consisted of five patient cases, which were presented as a panel discussion involving three faculty members. One faculty member served as a moderator to facilitate discussion, while two faculty members assessed the patient case and provided different clinical opinions (at times in a debate-style format) as to the appropriate treatment of the patient using the guidelines discussed in hours 1-2 to support their recommendations. Because the three faculty members practice in different clinical areas, both ambulatory care and internal medicine, the responsibility for assessing the patient case and providing recommendations rotated through all panel members in a "roundrobin" format. The purpose of this panel discussion was to allow the faculty members to role model critical thinking in the application of all available clinical recommendations to a variety of different clinical scenarios, as well as demonstrate respectful interactions between health care providers with dissenting opinions. The students received a handout with guided questions for them to follow along as the faculty members presented the case, discussed multiple approaches to treating the patient and provided examples of ways to apply both the previous guidelines and the new guidelines to each patient (Appendix 1). This allowed the students to easily compare the two sets of newly released guidelines in the context of patient treatment. For some patient cases, primary literature was presented and evaluated to enhance the applicability of all types of information to each patient. At the conclusion of each case, faculty panelists answered any student questions, and the students then participated in an audience response question to ensure that they understood the major point of each case.
PP466 Hour 4: progressive patient case. The final hour of lecture consisted of an interactive, progressive patient case modeled after the patient cases in the panel discussion. Again, a handout with guided questions was provided for the students to use as they worked through the patient case, involving all available sets of dyslipidemia guidelines. The hour was designed so that the instructor presented the case in stages, allowing the students to evaluate the patient one step at a time (4-5 questions) individually first, then allowing time for the students to convene in groups of two to three and discuss their answers. The instructor's role was to walk around the room during the student work periods and answer questions to facilitate learning. At the end of each stage (4-5 questions), the instructor reviewed the answers to each question with the entire class and provided an audience response question to gauge student comprehension before moving to the next stage of the case. By the end of the hour, through the guided patient case, the students initiated therapy for a dyslipidemia patient; reassessed the patient and reformulated the medication therapy plan when a clinical event occurred; reassessed and revised therapy when the patient failed the previously initiated therapy; added additional therapy for additional dyslipidemiarelated problems; identified potential adverse effects of all recommended medications; and provided counseling points for each drug recommended.

PP468: Practical Laboratory/Case Studies II: The companion practice laboratory and case studies course, PP468, provides a two-hour class period for students to continue the process of applying the therapeutics material directly to a patient case. This is a team-taught course requiring approximately 12-14 instructors each semester. Prior to each class, instructors receive a detailed facilitator guide outlining activities and grading responsibilities, and they review the content and flow in a briefing session with the case writer. Notably, no additional instructors were needed to implement the innovative activities, and the same pre-class preparation methods were used. Students were divided into small sections (15-16 students per group) for this course. Within these smaller sections, the students were subdivided into "pods" of 3-4 students for class assignments and discussion. Each student at the pod was given a letter, A-D, to identify his/her assigned activity during class times.

Typically, for case studies, students are assigned a patient case that coincides with the therapeutics content schedule; the assignment entails reviewing the patient case to identify drug therapy problems and formulating a therapeutic plan based on the patient's history, condition, and more. Each student composes a subjective data, objective data, assessment and plan (SOAP) note for the patient case and submits the note on the PCP Blackboard 


\section{American Journal of Pharmaceutical Education 2018; 82 (7) Article 6317.}

Learning Management System prior to class. In previous course offerings, the case studies class coinciding with dyslipidemia involved an assigned patient case for which students developed and electronically submitted a SOAP note prior to class, participated in class discussion about the patient case for the entire two-hour class period, and received a grade after class for the written SOAP note assignment. Beginning in spring 2014 and continuing for all subsequent offerings, the SOAP note exercise was used to engage the students in alternative activities to enhance their critical decision-making skills. In addition to the SOAP note, the case studies activities were comprised of a varying combination of three parts: jigsaw and group evaluation of journal articles, completion of a mock United States Food and Drug Administration (FDA) MedWatch report of an adverse drug event, and group review of patient cases with an immediate feedback assessment tool (IFAT). ${ }^{16-18}$ The students were also evaluated for their communication and participation throughout the class duration using a course-specific rubric.

PP468 Part 1. The first activity in the class involved evaluation of a journal article related to treatment of statin induced myalgia. Prior to class, students were assigned to read one of four articles addressing the appropriate treatment for this adverse effect (specifically, each student within each pod was assigned a different article to read). Student article selection was determined by pod letter (eg, pod seat "A," pod seat "B," etc). Students were required to evaluate their assigned article with a technique previously unknown to them, the PIES method (population, intervention, endpoints, statistics), and bring a completed PIES worksheet with them to class. ${ }^{15}$ In the spring 2014 course offering, students met in groups based on article assigned (eg, all students with article " $A$ " met together, all students with article "B" met together, etc.) to discuss the article at the beginning of class in a jigsaw technique. ${ }^{16}$ Subsequently, and at the beginning of class in all future course offerings, students met in pods to discuss all of the assigned articles and use the information from all of the articles to come to a consensus on their pod's recommendation for treatment for a specific patient case involving the known adverse drug event. Each pod then participated in a class discussion with the section facilitator about all of the articles and the pertinent information gleaned to make an appropriate treatment decision. The first hour of class time was allotted to this activity.

PP468 Part 2. The second activity involved completion (without submission) of a United States Food and Drug Administration (FDA) MedWatch form on behalf of the patient in the case from Part 1 of class. This was a new exercise for the students in PP468, and notably, this was new to the curriculum as the only opportunity to practice completion of the form. This activity was evaluated and graded for completion; approximately 20 minutes of the second hour of the class period was allotted to this activity.

PP468 Part 3. The final 40 minutes of the class period involved student pod evaluation of patient cases with the use of an answer tool, specifically the Immediate Feedback Assessment Technique (IFAT) card. IFAT cards are designed like a lottery ticket with 10 rows comprised of answer choices A through E. Each letter option within the row is hidden by a silver material that can be removed by scratching the card with a coin or other object; the correct letter answer contains a star underneath the scratch-off material. Students reviewed multiple patient cases, followed by a multiple-choice question associated with each case. After coming to a group consensus on the correct answer for each question, they used the IFAT card and "scratched off" their choice. If the first scratch-off was not the correct answer, the students moved on to their second choice, then third choice, etc. Full credit was given to the group for each question when the correct answer was chosen on the first attempt, with partial credit given for each attempt thereafter. This allowed students to professionally collaborate to solve a patient-related problem while also receiving immediate feedback on their answer choices. Facilitators briefly reviewed the cases with the students after submission of the card.

Formal assessment of these strategies occurred through multiple avenues. First, the students answered multiple choice audience response (TurningPoint) questions during all four hours of the PP466 didactic class period. These questions were graded for credit, but each question (and all answer choices) was discussed during the class period immediately after answers were submitted. Second, the second examination for PP466 included nine questions that tested the students' knowledge of dyslipidemia and ability to apply available treatment options to a specific patient case. Third, students were asked to complete an evaluation of the PIES method for evaluating journal articles in PP468; the purpose of this evaluation was to gauge their ability to use the tool and interest in using it in the future. Finally, most of the assignments in the PP468 class were evaluated and graded.

The University of the Sciences Institutional Review Board approved research on this innovation under an exempt status. Descriptive statistics were used for all evaluations.

\section{RESULTS}

Results of the PP466 in-class audience response questions are summarized in Table 3. TurningPoint questions were provided to the students throughout the four live lecture hours. During hours 1 and 2, the questions 


\section{American Journal of Pharmaceutical Education 2018; 82 (7) Article 6317.}

Table 3. Correct Responses to Turning Point Audience Response Questions

\begin{tabular}{lccc}
\hline & Spring 2014 \% (range) & Spring 2015 \% (range) & Spring 2016 \% (range) \\
\hline Hours 1-2 & $89(77-97)$ & $86(74-98)$ & $87(75-99)$ \\
Hour 3 & $\mathrm{n}=190$ & $\mathrm{n}=163$ & $\mathrm{n}=161$ \\
& $91(85-98)$ & $89(80-98)$ & $90(81-99)$ \\
Hour 4 & $\mathrm{n}=189$ & $\mathrm{n}=169$ & $\mathrm{n}=167$ \\
& $\mathrm{~N} / \mathrm{A}^{\mathrm{a}}$ & $89(80-98)$ & $90(81-99)$ \\
\end{tabular}

${ }^{a}$ Data were unavailable for Hour 4 in Spring 2014 because the progressive patient case was provided via Panopto video capture software (due to a severe weather emergency)

focused on recall of didactic content and served as a review for the information presented immediately preceding the question. During hour 3 (the panel discussion), the questions focused on specific aspects of the patient cases and served as a method of summarizing the most important point(s) of each case. During hour 4 (interactive student-driven progressive patient case), the questions encompassed information from all four hours of the didactic class period to serve as an overall review. Students overall performed very well on these questions, indicating at least a basic understanding of the material (Table 3).

Examination performance for the dyslipidemia content on the PP466 examination is summarized in Table 4. Content included a combination of multiple choice, extended multiple choice, matching, and short answer questions, with slight formatting variations throughout the multiple course offerings; performance data was not available for non-multiple-choice questions. Two versions of the examination were offered each year with the same questions included, but in a different order, to prevent academic dishonesty. In general, students performed well on both versions of the examinations in all years. The biserial value of each question was analyzed as a marker of discrimination, with the target biserial value $>.3$ but acceptable values $>0$ depending on the percentage of the class that answered the question correctly. Of note, while the overall concepts tested did not vary between the years, the focus of the content shifted (ie, less focus on historical treatment approaches and increased emphasis on new and updated treatment guidelines from 2014 to 2016).
Students completed the PP468 in-class evaluations at the conclusion of class in the 2014 and 2015 course offerings. A survey presented five questions specific to the PIES method and in-class activities, with answer choices of "strongly agree," "agree," "undecided," "disagree," and "strongly disagree." For the purposes of evaluating this exercise, responses that were either "strongly agree" or "agree" were considered positive, "undecided" was a neutral response, and "disagree" or "strongly disagree" were considered negative responses. The overall evaluation was positive and results for specific questions are summarized in Figure 1 (data presented in aggregate; neutral responses not shown). Additionally, all students received a communication/participation grade during the case activities in all spring semesters from 2014 to 2016, with students scoring well above $90 \%$ on average for all three years (data not shown).

Student evaluation of the innovation was overwhelmingly positive based on formal course evaluations of PP466 in all three semesters. Students were asked to answer 10 questions specific to the instructor of each disease state module, with answer choices similar to those listed above. Specific questions on the evaluation and results of the course evaluations are summarized in Figure 2 (presented as aggregate data for the spring 2014, spring 2015 and spring 2016 semesters; neutral responses not shown). Of note, the same faculty member taught the dyslipidemia module across all three semesters. In addition, students provided comments regarding the innovation in both PP466 and PP468 that are summarized in Appendix 2. The comments were overall positive, with

Table 4. PP466 Examination Performance

\begin{tabular}{llccc}
\hline & & Multiple-Choice (\#) & Average Score (mean, \%) & Biserial $>\mathbf{. 3}(\mathbf{\%})^{\mathbf{a}}$ \\
\hline Spring 2014 & Exam A & 6 & 82 & 67 \\
& Exam B & 6 & 81 & 50 \\
Spring 2015 & Exam A & 7 & 75 & 71 \\
& Exam B & 7 & 77 & 29 \\
Spring 2016 & Exam A & 5 & 83 & 20 \\
& Exam B & 5 & 81 & 20 \\
\hline
\end{tabular}

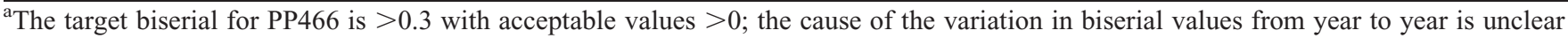




\section{American Journal of Pharmaceutical Education 2018; 82 (7) Article 6317.}



Figure 1. Results of the PIES Survey in PP468 (2014 and 2015; $n=311$ ).

several areas of improvement noted. Finally, although this pharmacy college does not have a formal process for faculty/peer evaluation, several positive (unsolicited) comments were received from faculty instructors involved in PP468 after the case was completed; those are also summarized in Appendix 2.

\section{DISCUSSION}

The overwhelmingly positive student (and faculty) reaction to the novel teaching approach indicated that the original purpose in redesigning the dyslipidemia module was accomplished. This original purpose was to enhance the students' ability to apply the information to appropri- ate patient treatment, the achievement of which was exemplified in the following: very high scores on hour 3 of the PP466 TurningPoint questions, where the questions centered around appropriate patient care vs didactic content; performance on the PP466 examination questions; performance on the pod summary recommendations and IFAT cards activities in PP468 (data not shown); and the subjective student and faculty comments regarding the learning experience during both courses (Tables 3, 4, Figure 2, Appendix 2). The consistent theme of the comments was that the students felt better prepared to apply the content in practice as compared to previous disease state modules.



Figure 2. PP466 Course Evaluation Responses (2014-2016; n=230). 


\section{American Journal of Pharmaceutical Education 2018; 82 (7) Article 6317.}

Another equally important goal of this teaching approach involved increasing student engagement in the course, wherein students would focus on why the information was important to learn for patient care, as opposed to simply memorizing the information with the intent to regurgitate the information on an examination. The success of this was reflected in the following: PP466 course evaluations (specifically the positive response to the questions "instructor stimulated interest in learning material" and the subjective student comments); PP468 student evaluations of the PIES method of evaluating literature; and the subjective student and faculty comments regarding the learning experience during PP468. Cumulatively, this innovation addressed most aspects of ACPE Standard 10.12, including facilitation of achieving learning outcomes, learner engagement, and student selfdirected and collaborative learning. ${ }^{12}$

Although active learning activities are preferred to traditional didactic lecturing in many disciplines, large classroom sizes and limited resources often present seemingly insurmountable barriers to adoption of these approaches. ${ }^{19}$ The class size at this pharmacy college averages approximately 200 students, comprising one of the largest pharmacy class sizes in the nation. Due to the number of students that must be accommodated, many of the required courses meet in large lecture hall settings with limited ability for students to interact with either each other or the faculty instructor. Logistically, this presents a challenge for faculty attempting active-learning exercises that require teaching methods beyond traditional didactic lecture. The authors sought to overcome these barriers through use of active learning techniques that can be extrapolated to and implemented in a classroom of any size and with any discipline. Audience response questions have been shown to improve student focus and motivation and are easily employed in any learning environment. ${ }^{20-23}$ Literature exists in pharmacy education regarding the success of student-led debates in exploring clinical controversies, but very limited data involves the use of faculty-led debates, modeled for students, to convey the daily decision-making process that health care practitioners undergo. ${ }^{24-26}$ While many pharmacy colleges require students to participate in communication development, students often receive extensive training in pharmacist-patient communication and considerably less training in pharmacist-health care practitioner communication. As a faculty panel, the authors were able to model not only the decision-making process, but the ability to both agree and disagree with each other in a professional manner that was supported entirely by evidence and sound reasoning. They demonstrated how multiple health care practitioners can be correct and evi- dence-based while still reaching different conclusions, an important realization for pharmacy students who will soon enter a patient care world where nearly all decisions will possess some degree of ambiguity. ${ }^{27}$ Through the use of an interactive patient case in the final hour of the lecture time, students had the opportunity to take responsibility for developing their own patient care plans without concern for grade or patient outcome; they were allowed to apply information to a patient in a partial flipped classroom format in a low-stakes environment. They collaborated within their peer groups - and yet still received guidance from the instructor - while evaluating cases that many times had multiple correct answers. The case itself followed one patient through many stages of the disease, requiring modifications of previous therapy decisions in a manner that commonly occurs in practice. Finally, the patient cases employed during the panel discussion and interactive exercise involved actual patients from the faculty practice sites, which enhanced the applicability of student knowledge in their future careers. These methods could certainly be employed, perhaps even more effectively, in a smaller class size or in a room designed for more consistent interaction between individuals participating in the course. This allows essentially all pharmacy colleges to use these teaching strategies as necessary to enhance learning.

Within the current PharmD curriculum at this school, the lecturer for the dyslipidemia didactic material has already implemented the interactive patient case (Hour 4) style of presentation in two other courses in the disease state management sequence. Notably, the content modules in the other courses focus on pain management and chronic kidney disease, both very different disease states than dyslipidemia. Therefore, this lecture style can be successfully used for essentially any disease state regardless of content. Of interest, in the spring 2014 offering of PP466, Hour 4 of the dyslipidemia lecture (the interactive patient case) was recorded using Panopto video software (Seattle, WA) and delivered to the students via Blackboard (Washington, DC) for independent work due to a snow emergency. However, in the spring 2015 and spring 2016 offering of the course, the instructor was able to offer the interactive patient case in a live lecture environment as it was originally designed, with very positive anecdotal student feedback and overall success. This demonstrates the versatility of this method of instruction in multiple environments with varied levels of technology.

Several revisions to this innovation have occurred since the first offering in spring 2014. First, in some sections of PP468 in spring 2014, students were unable to complete the MedWatch form electronically as designed due to technology issues in the classroom. Instead of 


\section{American Journal of Pharmaceutical Education 2018; 82 (7) Article 6317.}

completing forms individually, students had to work in large groups and observe only a few students completing the forms. Therefore, to ensure adequate exposure to the MedWatch form prior to future offerings of the course, the computers in the classroom for PP468 were tested for functionality prior to class. If Blackboard was not functional, the FDA website was made available as backup. If the internet was not functional, paper copies of the form were made available. Students then had the opportunity to complete the exercise individually for maximum understanding. Second, while the PIES journal article evaluation exercise is well designed for analysis of single clinical trials, its usefulness is less clear when used to analyze systemic reviews of multiple trials. ${ }^{15}$ Several students noted this concern in their comments (Appendix 2), specifically that the differences in students' abilities to thoroughly evaluate the articles and lack of prior training on the method created difficulty in group discussions while formulating patient care plans with the information. The same articles were used for the 2015 and 2016 course offerings but talking points were provided for section facilitators to address these concerns and guide the students through evaluation of the PIES process as part of the group discussion. Of note, the MedWatch form and the IFAT cards were not used in the spring 2016 offering of this course in favor of an activity focusing on health literacy.

As the college undergoes a curricular revision (currently in process), faculty members are seeking creative teaching techniques that better prepare students for careers after graduation, and the approach to this course module has been offered as an example to pharmacy practice, pharmaceutical sciences, and pharmacology/ toxicology faculty colleagues interested in revising their traditional approaches. However, these exercises are not solely useful as part of pharmacy education. The panel discussion between faculty members and the interactive, group discussion techniques used in PP466 can be successfully applied to all large classrooms for essentially any lecture content. Notably, new guidelines or recommendations emerge every few years for many disciplines and specialties, and faculty members are faced with the task of reworking instructional materials while presenting multiple perspectives. Application of these techniques not only allows students to distinguish between various recommendations, but they also allow students to visualize how a specialist would navigate what can be overwhelming and conflicting data.

Several limitations to this study exist. The most significant limitation is the lack of baseline data from prior course offerings, specifically audience response system and question-level examination data, to definitively dem- onstrate an improvement with this innovation. Also, these significant changes were implemented the first year that the authors taught this disease state module, and many of the methods employed were new to both courses, thereby preventing a direct comparison with previous years. However, there was sufficient literature to support the use of active learning and guide student application of content, and the ACPE Standards emphasize the use of these techniques. Therefore, the authors believe that the innovation was a worthy endeavor and can be used as a template for others seeking to diversify their pedagogical approaches. ${ }^{12,13}$ Secondly, the authors were unable to evaluate long-term retention of content, which is the goal of increasing active learning and engagement. This study focused on course-level performance and engagement, so future studies would be required to demonstrate that this innovation leads to improved application in future courses or experiential rotations. Finally, students did not receive training on the PIES method prior to class, which likely inhibited their ability to maximally use the tool. Although additional student instruction regarding the PIES method has been considered, discussions are ongoing about the optimal literature evaluation method for the new curriculum at the college, and future iterations of this innovation will likely implement the selected method with standardized training across multiple courses.

\section{CONCLUSION}

Extensive literature in recent years has guided educators away from a traditional didactic lecture method and into the use of more innovative approaches to present complicated content. ${ }^{14,16-18,20-30}$ The ability to transition from rote memorization to application in the clinical setting can be enhanced by faculty modeling and increased student engagement. In redesigning the dyslipidemia module, the authors attempted to demonstrate how the didactic content could be applied in multiple situations that the students will encounter in the course of their careers, specifically: interactions with other health care professionals (panel discussion in PP466); determining appropriate treatment for a specific patient (Hour 4 of PP466 and Part 1 of PP468); evaluating literature for application to a patient case (Hour 3 of PP466 and Part 1 of PP468); reporting adverse events to appropriate entities (Part 2 of PP468); and working in teams to develop a drug therapy plan (Hour 4 of PP466 and all of PP468). The positive student reaction and performance indicated that they were engaged in the exercises and used the opportunity to enhance understanding of the material, so that they will be better equipped to apply the knowledge that they have gained to their professional lives as 


\section{American Journal of Pharmaceutical Education 2018; 82 (7) Article 6317.}

pharmacists. Overall, these extensive innovations allow pharmacy students exposure to the overall management of this disease state with approaches that can be repeated in other courses and disciplines to enhance learning.

\section{ACKNOWLEDGMENTS}

The authors thank Dr. Laura LoCastro Bio for her assistance in course design and implementation of the innovation in the PP468: Practical Lab/Case Studies II course for the spring 2014 semester.

\section{REFERENCES}

1. Stone NJ, Robinson JG, Lichtenstein AH, et al. 2013 ACC/AHA Guideline on the treatment of blood cholesterol to reduce atherosclerotic cardiovascular risk in adults. Circulation. 2014;129: S1-S45.

2. Jacobson TA, Ito MK, Maki KC, et al. National Lipid Association recommendations for patient-centered management of dyslipidemia: part 1 - full report. J Clin Lipidol. 2015;9(2):129-169.

3. Jacobson TA, Maki KC, Orringer C, et al. National Lipid Association recommendations for patient-centered management of dyslipidemia: part 2. J Clin Lipidol. 2015;9(6):S1-S122.

4. National Cholesterol Education Program (NCEP) Expert Panel on Detection, Evaluation, and Treatment of High Blood Cholesterol in Adults (Adult Treatment Panel III). Third report of the National Cholesterol Education Program (NCEP) Expert Panel on Detection, Evaluation, and Treatment of High Blood Cholesterol in Adults (Adult Treatment Panel III) final report. Circulation. 2002;106(25): 3143-3421.

5. Grundy SM, Cleeman JI, Merz CN, et al. Implications of recent clinical trials for the National Cholesterol Education Program Adult Treatment Panel III guidelines. Circulation. 2004;110(2):227-239. 6. Finkel JB, Duffy D.2013 ACC/AHA cholesterol treatment guidelines: paradigm shifts in managing atherosclerotic cardiovascular disease risk. Trends Cardiovasc Med. 2015;25(4): 340-347.

7. Gotto AM, Moon JE. Merits and potential downsides of the 2013 ACC/AHA cholesterol management guidelines. Nutr Metab Cardiovasc Dis. 2014;24(6):573-576.

8. Robinson JG. 2013 ACC/AHA cholesterol guideline for reducing cardiovascular risk: what is so controversial? Curr Atheroscler Rep. 2014;16(6):413.

9. Adhyaru BB, Jacobson TA. New cholesterol guidelines for the management of atherosclerotic cardiovascular disease risk: a comparison of the 2013 American College of Cardiology/American Heart Association cholesterol guidelines with the 2014 National Lipid Association recommendations for patient-centered management of dyslipidemia. Cardiol Clin. 2015;33(2):181-196 10. Waite LH, Phan YL, Spinler SA. What's next for dyslipidemia management? The 2013 ACC/AHA guidelines, the NLA recommendations, and beyond. J Am Pharm Assoc. 2016;56(3): 284-292.

11. Medina MS, Plaza CM, Stowe CD, et al. Center for the Advancement of Pharmacy Education educational outcomes 2013. Am J Pharm Educ. 2013;77(8):Article162.

12. Accreditation Council for Pharmacy Education. Accreditation standards and key elements for the professional program in pharmacy leading to the doctor of pharmacy degree. Standards 2016. https:// www.acpe-accredit.org/pdf/Standards2016FINAL. pdf. 13. Accreditation Council for Pharmacy Education. Guidance for the accreditation standards and key elements for the professional program in pharmacy leading to the doctor of pharmacy degree. Guidance for Standards 2016. https://www.acpe-accredit.org/pdf/ GuidanceforStandards2016FINAL.pdf.

14. Gleason BL, Peeters MJ, Resman-Targoff BH, et al. An activelearning strategies primer for achieving ability-based educational outcomes. Am J Pharm Educ. 2011;75(9):Article 186.

15. Baroletti S, Szumita PM. PIES method of critique. Crit Pathw Cardiol. 2004;3(4):205-208.

16. Aronson E. The Jigsaw Classroom: overview of the technique. https://www.jigsaw.org/\#steps. Accessed May 19, 2017.

17. Phillips J, Fusco J. Using the Jigsaw technique to teach clinical controversy in a clinical skills course. Am J Pharm Educ. 2015;79(6): Article 90.

18. Earl GL. Using cooperative learning for a drug information assignment. Am J Pharm Educ. 2009;73(7):Article 132.

19. Bonwell CC, Eison JA. Active Learning: Creating Excitement in the Classroom. Washington, DC: George Washington University Press; 1991.

20. Cain J, Black EP, Rohr J. An audience response system strategy to improve student motivation, attention, and feedback. Am J Pharm Educ. 2009;73(2):Article 21.

21. Abdel Mequid E, Collins M. Students' perceptions of lecturing approaches: traditional versus interactive teaching. Adv Med Educ Pract. 2017;8:229-241.

22. Grzeskowiak LE, Thomas AE, To J, Phillips AJ, Reeve E. Enhancing education activities for health care trainees and professionals using audience response systems: a systematic review. $J$ Contin Educ Health Prof. 2015;35(4):261-269.

23. DiVall MV, Hayney MS, Marsh W, et al. Perceptions of pharmacy students, faculty members, and administrators on the use of technology in the classroom. Am J Pharm Educ. 2013;77(4): Article 75.

24. Lampkin SJ, Collins C, Danison R, Lewis M. Active learning through a debate series in a first-year pharmacy self-care course. Am J Pharm Educ. 2015;79(2):Article 25.

25. Charrois TL, Appleton M. Online debates to enhance critical thinking in pharmacotherapy. Am J Pharm Educ. 2013;77(8):

Article 170.

26. Lin SJ, Crawford SY. An online debate series for first-year pharmacy students. Am J Pharm Educ. 2007;71(1):Article 12.

27. Brown DL. Rethinking the role of clinical practice guidelines in pharmacy education. Am J Pharm Educ. 2015;79(10):Article 148. 28. Marshall LL, Nykamp DL, Momary KM. Impact of abbreviated lecture with interactive mini-cases vs traditional lecture on student performance in the large classroom. Am J Pharm Educ. 2014;78(10): Article 189.

29. Lichvar AB, Hedges A, Benedict NJ, Donihi AC. Combination of a flipped classroom format and a virtual patient case to enhance active learning in a required therapeutic course. Am J Pharm Educ. 2016;80(10):Article 175.

30. Rotellar C, Cain J. Research, perspectives, and recommendations on implementing the flipped classroom. Am J Pharm Educ. 2016;

80(2):Article 34. 


\section{American Journal of Pharmaceutical Education 2018; 82 (7) Article 6317.}

Appendix 1. Example of Student-Guided Handout for Hours 3-4 of PP466 (2016)

\section{$\underline{\text { Hour \#3 - Dyslipidemia Panel Discussion }}$}

\section{Patient Case \#1}

PP is a 54-year-old African American male with a past medical history of hypertension, depression and BPH who presents to his primary care physician's office for his regular check-up. He has no significant family history, and he does not smoke. His blood pressure at the office is 150/74 which he states is normal for him since he started lisinopril. His BMP, CBC, LFT and TSH are all within normal limits. His lipid panel is as follows: TC 270, HDL-C 42, TG 282, LDL-C 172. How should this patient be treated?

ATP III

Primary target of therapy:

Secondary target of therapy:

What are his LDL goal-modifying risk factors?

What is his 10-year risk of a coronary heart disease event (Framingham Risk Score)?

What are his goals of therapy? Primary:

Secondary:

How much LDL-C reduction will this patient require to get to goal?

2013 ACC/AHA Blood Cholesterol Guideline

Primary target of therapy:

What is PP's goal of therapy?

What major statin benefit group does PP belong to?

Does he qualify for high-intensity statin therapy or moderate-intensity statin therapy?

NLA Recommendations (Parts 1-2)

Primary target(s) of therapy:

Secondary target of therapy:

Is the patient in a high-risk or very high-risk patient group?

What are his major ASCVD risk factors? (hint: see LDL goal-modifying risk factors above)

What is his 10-year risk of a coronary heart disease event (Framingham Risk Score)?

What is his 10-year risk of ASCVD (Pooled Cohort Equations)?

What risk category is this patient in (very high, high, moderate, or low risk)?

What are his goals of therapy? non-HDL-C: LDL-C:

How much LDL-C reduction will this patient require to get to goal?

Drug Therapy Plan: 


\section{American Journal of Pharmaceutical Education 2018; 82 (7) Article 6317.}

Appendix 2. Selected Comments from Evaluations of the Innovations in PP466 and PP468



